\title{
Combined Theoretical and Experimental Study of Nordihydroguaiaretic Acid - From Traditional Medicine to Modern Spectroscopic Research
}

\author{
Felicia S. Manciu 1,2,* (D), Jose Guerrero ${ }^{\text {, }}$, David Rivera ${ }^{\text {, }}$, Su-Youne Chang ${ }^{3,4}$, Kevin E. Bennet ${ }^{3,5}$ \\ 1 Department of Physics, University of Texas at El Paso, El Paso, TX 79968, USA; fsmanciu@ @utep.edu; \\ jaguerrero9@miners.utep.edu; dhrivera@miners.utep.edu; \\ 2 Border Biomedical Research Center, University of Texas at El Paso, El Paso, TX 79968, USA; fsmanciu@utep.edu \\ 3 Department of Neurologic Surgery, Mayo Clinic, Rochester, MN 55905, USA; Chang.SuYoune@ mayo.edu; \\ Bennet.Kevin@mayo.edu; \\ 4 Department of Physiology and Biomedical Engineering, Mayo Clinic, Rochester, MN 55905, USA; \\ Chang.SuYoune@mayo.edu; \\ 5 Division of Engineering, Mayo Clinic, Rochester, MN 55905, USA; Bennet.Kevin@ mayo.edu \\ * Correspondence: fsmanciu@utep.edu;
}

Scopus Author ID 6602690735

Received: 4.05.2020; Revised: 24.05.2020; Accepted: 24.05.2020; Published: 27.05.2020

\begin{abstract}
Combined theoretical and experimental analysis is utilized in this work to spectroscopically examine nordihydroguaiaretic acid's (NDGA) biomechanistic structure-function relationships that are related to its efficacy in preventing and treating various diseases or in generating toxicological effects. Although the medicinal and antiviral properties of this chemical extract from the Larrea tridentata plant have been studied in vitro and in vivo, an accurate distinction between its morphological changes had not yet been optically identified and reported. Obvious trends in vibrational signatures of NDGA's confirmations were successfully elucidated here. Our findings showed that the absence of the Raman feature at $780 \pm 5 \mathrm{~cm}^{-1}$ is indicative of a fully oxidized NDGA form, which, together with the orthoquinone, is likely to create the compound's bio-toxicity through accumulation. Other characteristic signatures of these toxic forms are the $1582 \pm 1 \mathrm{~cm}^{-1}$ and $1698 \pm 1 \mathrm{~cm}^{-1}$ Raman lines, and the $1680 \pm 17$ $\mathrm{cm}^{-1} \mathrm{IR}$ vibrational line. If the development of new drugs and their effective implementation is further envisioned, potentially even for COVID-19 pandemic, this study provides some needed comprehension in optically assessing important morphological changes that occur for this plant-derived compound due to its oxidation and creation of metabolites.
\end{abstract}

Keywords: Nordihydroguaiaretic acid (NDGA); Raman spectroscopy; Fourier-transformed infrared (FTIR) absorption spectroscopy; quantum chemical density functional theory (DFT) calculations; traditional medicine; biomaterials; drug delivery; COVID-19

(c) 2020 by the authors. This article is an open-access article distributed under the terms and conditions of the Creative
Commons Attribution (CC BY) license (https://creativecommons.org/licenses/by/4.0/).

\section{Introduction}

Traditional medical practices, developed over generations for treatment or prevention of various diseases, have been a cradle for the discovery of numerous chemical formulations and pharmaceutical drugs [1-7]. Although modern medical knowledge's continuous advancement has departed from that of traditional medicine, occasionally, it has returned to this source of discovery, to critically and scientifically evaluate alternative medicine's efficacy, and to create an understanding of its underlying bio-mechanisms. Evidence of the medical value of nordihydroguaiaretic acid (NDGA), the main extract from Larrea tridentata plant, 
came from traditional medicine [1,8-11]. This branched and knotty shrub, commonly found in the arid desert regions around El Paso, Texas, Northern Mexico, and Argentina, belongs to the Zygophyllaceae family [1,8-11]. In English, the plant is known as Creosote bush, Chaparral, and Greasewood. In Spanish, because of its strong scent, it is known as Hediondilla, which means a smelly little one, and Gobernadora, which means governess [1]. Despite the long history of Larrea tridentata in medicinal use for the treatment of more than 50 diseases, which includes renal, gallbladder, cancer, tuberculosis, rheumatism, diabetes, chronic skin disorders, cardiovascular and neurological [1,8-11], the plant utilization was prohibited in 1970 by the Food and Drug Administration (FDA) of the United States, and discouraged by the modern medical profession $[1,4,12,13]$. However, its prominent beneficial effects in alleviating so many significant diseases stimulated researchers' interest in investigating its phytochemistry [1,8-10,14-17] and understanding the mechanistic structure-function relationship of the plant's compounds to different treatments [18-27]. NDGA, the plant's most notable antioxidant compound, was first identified in 1945 [8], and chemically purified during 1955 [9]. Since then, isolation of 67 other compounds such as lignans, glycosylated flavonoids, oils, sapogenins, waxes, and halogenic alkaloids have been reported from this plant [14-17].

Initially, the radical scavenging and fluorescent effects of the plant-derived antioxidants in solutions were studied. Later on, their cytotoxicity, inhibitory, antiviral, and anti-tumor activities in vitro in cell cultures and in vivo in animal experiments received significantly more attention [18-42]. The four phenolic hydroxyl groups of NDGA's chemical structure were assumed to be primarily responsible for scavenging reactive oxygen species (ROS) such as hydroxyl radicals, singlet oxygen, superoxide anion, hydrogen peroxide, peroxynitrite, and hypochlorous acid. Since ROS are known to form in significant quantities in living organisms and damage biomolecular structures through oxidative stress processes, it enhanced the importance of NDGA employment as an antioxidant and the abundance of these research reports [18-34]. For example, it has been demonstrated that NDGA inhibits $\alpha$-synuclein aggregation and amyloid $\beta$-peptide through oxidation-dependent processes [21,22]. Also, studies of anti-tumorigenic and anti-proliferative mechanisms of NDGA showed suppression of tumor growth through inhibition of metabolic enzymes and receptor tyrosine kinases (RTK) phosphorylation $[23,26]$. In the rodent model, it has been found that NDGA has a lipoxygenase inhibitory effect, as well as the capability of enhancing fatty acid oxidation rates via peroxisome proliferator-activated receptor $\alpha(\mathrm{PPAR} \alpha)$-dependent pathways [27]. Furthermore, when used as a lipoxygenase inhibitor, it has been reported that NDGA itself activated human transient receptor potential cation channel subfamily A (TRPA1) [28]. This finding of TRPA1 agonist activity for NDGA is important, as it implies a more complex therapeutic mechanism of action of this drug, besides those solely mediated by enzyme inhibition, antioxidant activity, or modulation of gene transcription [28]. Last but not least, concerning NDGA's antiviral properties, it has been reported that NDGA inhibits a large variety of viruses, such as dengue virus (DENV), hepatitis C virus (HCV), West Nile virus (WNV), Zika virus (ZIKV), influenza A viruses (IAV), herpes simplex virus (HSV), and human immunodeficiency virus (HIV) [20,35-43]. Since NDGA targets genome replication and viral assembly, this observation could be of critical value for the development of new drugs against the current COVID-19 pandemic.

A point of interest that was also considered and reported relates to the relationship between the NDGA's cytotoxic activity and that of pro-oxidant capability. It has been suggested that these two activities might be independent [44]. Concerning the reported hepatic and renal risks of NDGA, which were the main reasons for its FDA banning [45-47], additional 
studies proved that a non-renal mechanism was responsible for the compound clearing $[1,11,16,18]$. This statement is based on the NDGA's high clearance of $201.9 \mathrm{~mL} / \mathrm{min}$. ${ }^{*} \mathrm{~kg}$ $[1,16,18]$. Regarding the hepatic metabolism, it had been demonstrated that the compound potential extraction by the liver as O-methylation and glutathione conjugation or by other metabolic derivatives, significantly changed NDGA's in vivo toxicity [16,18]. Furthermore, a two-compartment pharmaco-kinetic profile was reported for NDGA, with a half-life distribution of 30 minutes and a terminal half-life of 135 minutes [18]. Thus, despite the high compound affinity of binding to bioanalytes, which could limit its bioavailability in vivo, the NDGA's quite long terminal half-life could also permit the compound to accumulate to cytotoxic levels [18]. In this context, it is worth pointing out that there is still a need for further studies to provide a better assessment of NDGA's properties based on the compound's structure-function relationship.

Since the naturally occurring compound is optically inactive [10,47], the detection of NDGA's accumulation by these means has not yet been accomplished. However, when administrated as a drug, it has been reported to quench the fluorescence intensity of albumins by binding with the fluorophores present in proteins [48]. Although not a direct detection of NDGA itself, but of its interaction with major carrier proteins like serum albumins was optically obtained in this case, this observation has importance for understanding the transport and metabolism of the drug [48]. Theoretically, it has been predicted that NDGA absorption occurs in the UV-VIS spectrum, at about $280 \mathrm{~nm}$ [49]. Unfortunately, other NDGA's associated chemical conformations resulted from its oxidation or potential binding to analytes were predicted to absorb in the same optical region as well [49]. Thus, due to their close optical absorption proximity in UV-VIS, accurate discrimination between NDGA's morphological changes is experimentally infeasible, and not yet achieved. NDGA's identification is of substantial significance for understanding which specific compound conformation is associated with the drug toxicity and potential health threat, and which has beneficial effects.

Other optical methods that provide a more straightforward way of investigating chemical changes in the NDGA structure are Raman and Fourier transformed infrared (FTIR) vibrational spectroscopies. However, the lack of such reported results is quite surprising, especially that this compound was so intensely studied for its medicinal effects. Therefore, the goal of the current work is to provide, to the best of our knowledge for the first time, the optical vibrational modes for this compound and their corresponding tentative assignments. A combined experimental and theoretical approach between measurements and quantum density functional theory (DFT) computational results are presented and discussed here. Not only is such analysis bringing additional insights into NDGA bio-mechanism of action, but also to its toxicity effects.

\section{Materials and Methods}

\subsection{Spectroscopic Systems.}

NDGA $\left(\mathrm{C}_{18} \mathrm{H}_{22} \mathrm{O}_{4},>97 \%\right)$ was purchased from Sigma-Aldrich (Sigma-Aldrich Co.) and used as received. The Raman measurements were performed at ambient conditions with an alpha 300RAS WITec system (WITec GmbH, Ulm, Germany), using the $532 \mathrm{~nm}$ excitation of a frequency-doubled neodymium-doped yttrium-aluminum-garnet (Nd:YAG) laser and a 20X air objective lens (Olympus, Japan) with a numerical aperture (NA) of 0.4. The laser power was maintained at an output of a few $\mathrm{mW}$. Accumulations of 20 Raman spectra, with each 
spectrum acquired in 500 milliseconds, for total acquisition times of 10 seconds and spectral resolutions of $4 \mathrm{~cm}^{-1}$, were performed. Infrared (IR) studies were carried out under vacuum in transmission mode with a Bruker FTIR-IFS 66v (Bruker Optics Inc., Billerica, MA) system. The measurements in the mid-IR region were performed using a deuterated lanthanum $\alpha$ alanine doped triglycine sulfate (DLaTGS) detector and a potassium bromide $(\mathrm{KBr})$ beamsplitter (Bruker Optics Inc.). The samples for IR measurements were prepared as pellets by embedding the NDGA sample in a polycrystalline $\mathrm{KBr}$ matrix. An accumulation of 256 scans at a resolution of $4 \mathrm{~cm}^{-1}$ was recorded for this spectrum. The data were normalized to a vacuum throughput spectrum.

\subsection{Computational Analysis.}

The Gaussian-16 analytical suite software was employed for the quantum chemical density functional calculations. An energy optimization was performed prior to computing vibrational frequencies. For these analyses, the Becke three hybrid exchange [50] and the LeeYang-Parr correlation functional, B3LYP [51] were used. A 6-311++G(d,p) basis set was also employed for calculating the molecular form. The Gaussian-16 output data were parsed using an in-house algorithm developed in $\mathrm{C}++$, and subsequently converted to MATLAB version r2016a. In the case of Raman computed data, further conversion of Raman activities into relative Raman intensities was also performed, following a previously reported procedure [52]. A value of $532 \mathrm{~nm}=18,796.99 \mathrm{~cm}^{-1}$ was used in the current conversion for the laser excitation. To assist with data plotting, all the peak intensities from the estimated results were normalized by appropriate factors to match those experimentally obtained. Also, for easier visualization of theoretical outcomes, a Lorentzian band with a full width at half maximum (FWHM) of $7 \mathrm{~cm}^{-}$ ${ }^{1}$ was applied to broaden their shapes.

\section{Results and Discussion}

NDGA contains phenolic hydroxyl groups, which can act as proton donors or acceptors. However, because of its $\mathrm{pK}_{\mathrm{a}}$ value of 9.30, only on extremely basic conditions will these hydroxyl groups be dissociated [49]. The insolubility of the compound in water requires its prior solvation in small amounts of dimethylsulfoxide (DMSO), acetonitrile, or methanol for studies in aqueous solutions [49]. Thus, at normal physiological conditions, the neutral form of the compound is mostly expected and first analyzed here. The NDGA's energetically optimized molecular structure and the associated Raman vibrations are presented in Figure 1AC. The outcomes of computational analysis by DFT, which are shown in Figure 1B, are also compared in Figure 1C against experimentally acquired data on solid NDGA (recorded for chemical powder as received). A break between 1800 and $2500 \mathrm{~cm}^{-1}$ was applied to the spectra presented in Figure 1B and 1C to allow the inclusion of all regions of interest in the same figure. To overcome the systematic empirical errors originating from the force field constants employed in quantum DFT approaches $[53,54]$ and to increase the agreement between the peaks of the theoretically estimated frequencies and the measured ones, the calculated vibrations were scaled by a factor of 0.98 . Since even at a higher level of theoretical calculations, the complexity of experimental specifics cannot be entirely accounted for, such scaling factors have been previously used to reliably comprehend the vibrational assignments when compared with experimentally observed phenomena [55]. 
The most intense peak in Figure 1B, which can be regarded as a spectroscopic fingerprint for neutral NDGA, is observed at $785 \mathrm{~cm}^{-1}$ (measured at $790 \mathrm{~cm}^{-1}$ in Figure 1C). This vibrational signature, previously observed for dopamine [56,57], is somewhat expected considering the symmetry of the molecule, with two catechol rings at its ends. Other intense vibrational modes were measured at $744 \mathrm{~cm}^{-1}$ (calcd. at $740 \mathrm{~cm}^{-1}$ ), $1294 \mathrm{~cm}^{-1}$ (calcd. at 1300 $\mathrm{cm}^{-1}$ ), and $1623 \mathrm{~cm}^{-1}$ (calcd. at $1607 \mathrm{~cm}^{-1}$ ). Likewise, all these vibrations mainly arise from inplane deformations of the molecule's two catechol ring moieties, such as $v(C=C)$ and $v(C-O)$ stretching, and $\rho(\mathrm{C}-\mathrm{O}-\mathrm{H})$ rocking. Less significant contributions come from weak out-of-plane $\omega\left(\mathrm{CH}_{2}\right)$ and $\omega\left(\mathrm{CH}_{3}\right)$ wagging, and $\tau\left(\mathrm{CH}_{3}\right)$ twisting. The higher frequency range between 2800 $\mathrm{cm}^{-1}$ and $3100 \mathrm{~cm}^{-1}$ is dominated by $v_{\mathrm{s}}\left(\mathrm{CH}_{3}\right)$ and $v_{\mathrm{s}}\left(\mathrm{CH}_{2}\right)$ symmetric stretching of the aliphatic chain.
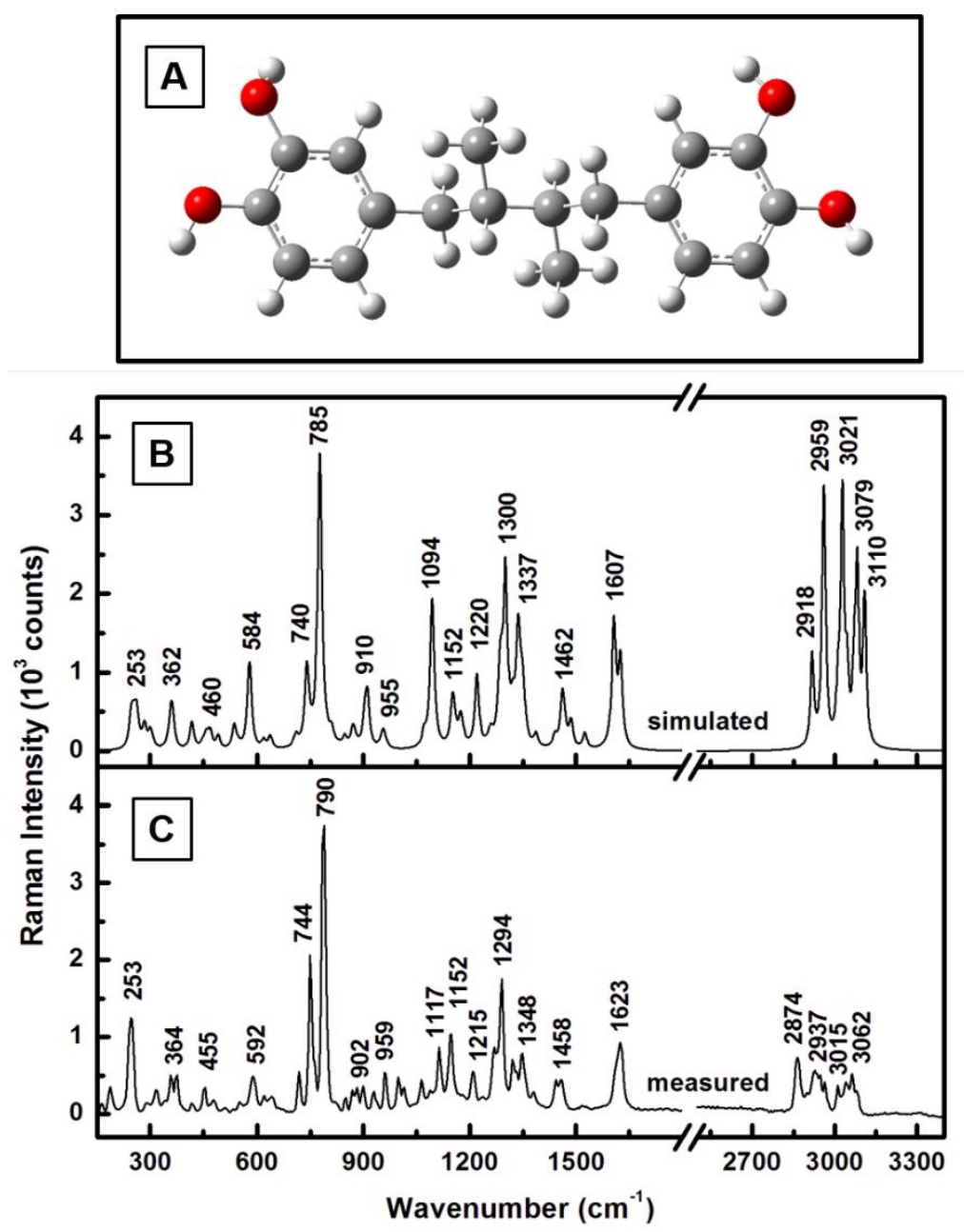

Figure 1. (A) Nordihydroguaiaretic acid (NDGA) structural representation in neutral form. Red color is used for oxygen atoms, dark grey color for carbon atoms, and a light grey color for hydrogen atoms. (B) and (C) Theoretically calculated and experimentally measured Raman vibrations of NDGA, respectively. The Raman spectrum was recorded for the standard NDGA powder.

Overall, a comparison between the Raman spectra presented in Figure 1B and 1C demonstrates a good agreement between the theoretically determined and the measured values of peak frequencies, with discrepancies of $5 \pm 2 \mathrm{~cm}^{-1}$, on average. These discrepancies become larger at higher frequencies, where some variations in peak intensities additionally can be observed, suggesting an overestimation of the force field constant used in the Gaussian simulations. The measured and computationally estimated values of the Raman vibrational modes, along with their tentative assignments, are summarized in Table 1. 
Table 1. Theoretically calculated and experimentally measured Raman vibrations of NDGA with their tentative assignments.

\begin{tabular}{|c|c|c|}
\hline Calculated $\left(\mathrm{cm}^{-1}\right)$ & Measured $\left(\mathrm{cm}^{-1}\right)$ & Assignment \\
\hline $253(\mathrm{~m})$ & $253(\mathrm{~s})$ & in-plane $\rho\left(\mathrm{CH}_{3}\right)$ strong rocking; out-of-plane $\omega(\mathrm{O}-\mathrm{H})$ weak wagging \\
\hline $362(\mathrm{~m})$ & $364(\mathrm{~m})$ & $\begin{array}{l}\text { in-plane } \rho(\mathrm{C}-\mathrm{H}) \text { strong aromatic rocking; out-of-plane } \omega(\mathrm{C}-\mathrm{O}-\mathrm{H}) \\
\text { weak wagging; out-of-plane weak benzene ring bending }\end{array}$ \\
\hline $460(w)$ & $455(w)$ & $\begin{array}{l}\text { in-plane } \rho(\mathrm{C}-\mathrm{O}-\mathrm{H}) \text { rocking; } \rho\left(\mathrm{CH}_{2}\right) \text { rocking; } v(\mathrm{C}-\mathrm{O}) \text { stretching; } \\
\text { out-of-plane } \omega(\mathrm{C}-\mathrm{H}) \text { weak wagging; benzene ring deformation }\end{array}$ \\
\hline 584(m) & 592(m) & $\begin{array}{l}\text { in-plane strong } \rho(\mathrm{C}-\mathrm{O}-\mathrm{H}) \text { rocking; } \rho\left(\mathrm{CH}_{2}\right) \text { rocking; in-plane benzene } \\
\text { ring rocking }\end{array}$ \\
\hline $740(\mathrm{~m})$ & $744(s)$ & $\begin{array}{l}\text { in-plane } v(\mathrm{C}=\mathrm{C}) \text { stretching; } v(\mathrm{C}-\mathrm{O}) \text { stretching; out-of-plane } \omega\left(\mathrm{CH}_{2}\right) \\
\text { and } \omega\left(\mathrm{CH}_{3}\right) \text { weak wagging; benzene ring bending }\end{array}$ \\
\hline $785(\mathrm{vs})$ & $790(\mathrm{vs})$ & $\begin{array}{l}\text { in-plane } \rho(\mathrm{C}=\mathrm{C}) \text { rocking; } v(\mathrm{C}-\mathrm{O}) \text { stretching; out-of-plane } \omega\left(\mathrm{CH}_{3}\right) \\
\text { very weak wagging; benzene ring deformation }\end{array}$ \\
\hline $910(\mathrm{~m})$ & $902(w)$ & $\begin{array}{l}\text { in-plane } v\left(\mathrm{CH}_{2}\right) \text { stretching; } v\left(\mathrm{CH}_{3}\right) \text { stretching; } \rho(\mathrm{C}-\mathrm{H}) \text { rocking; } \\
v(\mathrm{C}-\mathrm{O}-\mathrm{H}) \text { stretching; benzene ring deformation }\end{array}$ \\
\hline $955(w)$ & $959(\mathrm{~m})$ & $\begin{array}{l}\text { in-plane } v(\mathrm{C}=\mathrm{C}) \text { stretching; } v\left(\mathrm{CH}_{2}\right) \text { stretching; } \rho\left(\mathrm{CH}_{2}\right) \text { rocking; } \\
\text { benzene ring bending }\end{array}$ \\
\hline 1094(s) & 1117(m) & $\begin{array}{l}\text { in-plane } v(\mathrm{C}-\mathrm{O}-\mathrm{H}) \text { stretching; } \rho(\mathrm{C}=\mathrm{C}) \text { rocking; } \rho\left(\mathrm{CH}_{3}\right) \text { rocking; } \\
\rho\left(\mathrm{CH}_{2}\right) \text { rocking; out-of-plane } \tau\left(\mathrm{CH}_{3}\right) \text { twisting }\end{array}$ \\
\hline $1152(\mathrm{~m})$ & $1152(\mathrm{~m})$ & $\begin{array}{l}\text { in-plane } \rho(\mathrm{O}-\mathrm{H}) \text { rocking; } \delta(\mathrm{C}=\mathrm{C}-\mathrm{C}) \text { bending; } \rho(\mathrm{C}-\mathrm{H}) \text { rocking; } \\
\text { out-of-plane } \tau\left(\mathrm{CH}_{3}\right) \text { twisting }\end{array}$ \\
\hline $1220(\mathrm{~m})$ & $1215(\mathrm{~m})$ & $\begin{array}{l}\text { in-plane } \rho(\mathrm{O}-\mathrm{H}) \text { rocking; } \delta(\mathrm{C}=\mathrm{C}-\mathrm{C}) \text { bending; } \rho(\mathrm{C}-\mathrm{H}) \text { rocking; } \\
\text { out-of-plane } \tau\left(\mathrm{CH}_{3}\right) \text { twisting; benzene ring deformation }\end{array}$ \\
\hline $1300(\mathrm{~s})$ & 1294(s) & $\begin{array}{l}\text { in-plane strong benzene ring breathing; } \rho(\mathrm{C}-\mathrm{H}) \text { rocking; } \\
v(\mathrm{C}-\mathrm{O}) \text { stretching }\end{array}$ \\
\hline 1337(m) & $1348(\mathrm{~m})$ & $\begin{array}{l}\text { in-plane } v(\mathrm{C}=\mathrm{C}) \text { stretching; } v(\mathrm{C}-\mathrm{O}-\mathrm{H}) \text { stretching; } \\
\rho(\mathrm{C}-\mathrm{H}) \text { aromatic rocking; out-of-plane } \omega\left(\mathrm{CH}_{3}\right) \text { weak wagging; } \\
\text { out-of-plane } \tau\left(\mathrm{CH}_{3}\right) \text { weak twisting }\end{array}$ \\
\hline $1462(\mathrm{~m})$ & $1458(\mathrm{~m})$ & $\begin{array}{l}\text { in-plane } v(\mathrm{C}-\mathrm{O}) \text { stretching; } \rho(\mathrm{C}-\mathrm{H}) \text { rocking; ; } \rho(\mathrm{C}=\mathrm{C}) \text { rocking; } \\
\text { benzene ring deformation }\end{array}$ \\
\hline 1607(s) & $1623(\mathrm{~s})$ & $\begin{array}{l}\text { in-plane } \rho(\mathrm{C}-\mathrm{O}-\mathrm{H}) \text { rocking; } v(\mathrm{C}=\mathrm{C}) \text { stretching; } \\
\text { out-of-plane } \tau\left(\mathrm{CH}_{3}\right) \text { twisting }\end{array}$ \\
\hline $2918(\mathrm{~m})$ & 2874(s) & $v_{\mathrm{s}}\left(\mathrm{CH}_{3}\right)$ stretching; $v_{\mathrm{s}}\left(\mathrm{CH}_{2}\right)$ stretching; $v_{\mathrm{s}}(\mathrm{CH})$ stretching \\
\hline 2959(vs) & $2937(\mathrm{~m})$ & $v_{\mathrm{s}}\left(\mathrm{CH}_{3}\right)$ stretching; $v_{\mathrm{s}}\left(\mathrm{CH}_{2}\right)$ stretching; $v_{\text {as }}(\mathrm{CH})$ stretching \\
\hline $3021(\mathrm{vs})$ & $3015(\mathrm{~m})$ & $v_{\text {as }}\left(\mathrm{CH}_{3}\right)$ stretching; $v_{\text {as }}(\mathrm{CH})$ stretching \\
\hline $3079(\mathrm{~s})$ & $3052(\mathrm{~m})$ & $v_{\text {as }}\left(\mathrm{CH}_{3}\right)$ stretching; $v_{\text {as }}\left(\mathrm{CH}_{2}\right)$ stretching \\
\hline $3110(\mathrm{~s})$ & & $v_{\text {as }}\left(\mathrm{CH}_{3}\right)$ stretching; $v_{\text {as }}\left(\mathrm{CH}_{2}\right)$ stretching \\
\hline
\end{tabular}

For a complete investigation of neutral NDGA form, the complementary IR vibrations are analyzed in Figure $2 \mathrm{~A}-\mathrm{C}$. To point out differences in the IR and Raman vibrational signatures even for the same configuration of NDGA, in Figure 2A, blue arrows mark the displacement vectors associated with the theoretically most intense IR vibrational mode at 1168 $\mathrm{cm}^{-1}$ (measured at $1190 \mathrm{~cm}^{-1}$ ). Also, for consistency with the IR measurements that were performed in a transmission mode, an appropriate conversion was applied to theoretically estimated vibrations, too. At a glance, visibly more intense vibrations are observed in Figure $2 \mathrm{C}$ for the experimentally determined IR results than for the calculated ones presented in Figure 2B. This discrepancy, which was not obvious for the Raman data (see Figure 1B and 1C), can be explained by the sensitivity of IR measurements to water absorption, which is not taken into consideration in the current simulation. This remark is further supported by the strong IR absorption seen in Figure 2C in the $3000-3500 \mathrm{~cm}^{-1}$ region, which is known to be the characteristic region for water absorption. Raman measurements are not so much influenced by water absorption; consequently, a much lower inconsistency in vibration intensities is 
detected in this case. Besides the IR fingerprint vibrational line at $1190 \mathrm{~cm}^{-1}$ (calcd. at 1168 $\left.\mathrm{cm}^{-1}\right)$ corresponding to catechol's strong $\rho(\mathrm{O}-\mathrm{H})$ rocking and in-plane benzene ring asymmetrical stretching, other intense IR absorptions are observed at $1112 \mathrm{~cm}^{-1}$ (calcd. at 1098 $\mathrm{cm}^{-1}$ ), $1251 \mathrm{~cm}^{-1}$ (calcd. at $1256 \mathrm{~cm}^{-1}$ ), $1293 \mathrm{~cm}^{-1}$ (calcd. at $1291 \mathrm{~cm}^{-1}$ ), $1445 \mathrm{~cm}^{-1}$ (calcd. at $1441 \mathrm{~cm}^{-1}$ ), $1525 \mathrm{~cm}^{-1}$ (calcd. at $1525 \mathrm{~cm}^{-1}$ ), and $1615 \mathrm{~cm}^{-1}$ (calcd. at $1614 \mathrm{~cm}^{-1}$ ). Once more, these vibrations are primarily attributed to the catechol rings' deformations and in-plane breathing, with other contributions belonging to the aliphatic chain's fragments such as $\rho\left(\mathrm{CH}_{3}\right)$ rocking and $\tau\left(\mathrm{CH}_{2}\right)$ twisting, and aromatic out-of-plane $\tau(\mathrm{C}-\mathrm{H})$ twisting. Again, the spectra presented in Figure 2B and 2C reveal a relatively good agreement between the IR calculated and experimentally determined data, with an average difference between vibrational frequencies of $7 \pm 4 \mathrm{~cm}^{-1}$ in the $400-1800 \mathrm{~cm}^{-1}$ region and of $11 \pm 4 \mathrm{~cm}^{-1}$ in the $2500-3700$ $\mathrm{cm}^{-1}$ region. Scaling factors of 0.98 and 0.96 are used in this case for the computed frequencies at lower wavenumbers $\left(400-1800 \mathrm{~cm}^{-1}\right)$ and higher wavenumbers $\left(2500-3700 \mathrm{~cm}^{-1}\right)$, respectively. The measured and computationally estimated values of the IR vibrational modes, along with their tentative assignments, are summarized in Table 2.

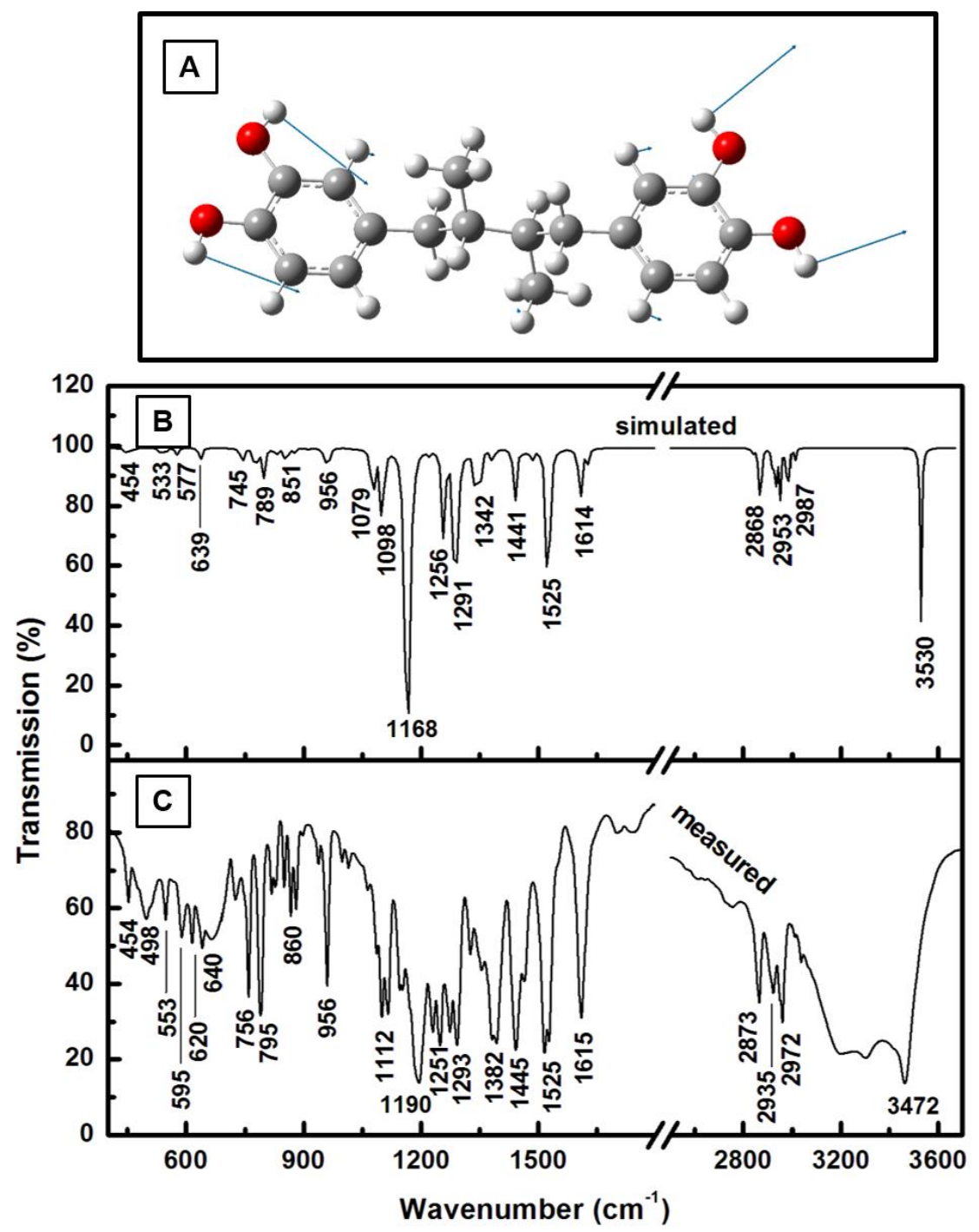

Figure 2. (A) Structural representation of neutral nordihydroguaiaretic acid (NDGA) form with displacement vectors for the most IR vibration at $1168 \mathrm{~cm}^{-1}$ represented by blue arrows. (B) and (C) Theoretically calculated and experimentally measured infrared transmission spectra of neutral NDGA, respectively. The KBr pellet technique was used for measurements. 
Table 2. Theoretically calculated and experimentally measured IR vibrations of NDGA with their tentative assignments.

\begin{tabular}{|c|c|c|}
\hline \multirow[b]{2}{*}{ Calculated $\left(\mathrm{cm}^{-1}\right)$} & \multirow{2}{*}{ Measured $\left(\mathrm{cm}^{-1}\right)$} & \\
\hline & & Assignment \\
\hline \multirow[t]{2}{*}{ 454(vw) } & $454(w)$ & $\begin{array}{l}\text { out-of-plane } \omega(\mathrm{C}-\mathrm{H}) \text { wagging; } v_{\text {as }}(\mathrm{C}=\mathrm{C}-\mathrm{C}) \text { stretching; } \rho\left(\mathrm{CH}_{2}\right) \text { rocking; } \\
\text { benzene ring bending }\end{array}$ \\
\hline & 498(w) & $\begin{array}{l}\text { out-of-plane } \omega\left(\mathrm{CH}_{3}\right) \text { wagging; in-plane } \rho(\mathrm{C}-\mathrm{O}-\mathrm{H}) \text { rocking; } \\
\rho\left(\mathrm{CH}_{2}\right) \text { rocking; benzene ring deformation }\end{array}$ \\
\hline 533(vw) & 553(w) & $\begin{array}{l}\rho(\mathrm{C}=\mathrm{C}) \text { rocking; } \delta\left(\mathrm{CH}_{2}\right) \text { and } \delta\left(\mathrm{CH}_{3}\right) \text { bending; out-of-plane } \tau(\mathrm{CH}) \text { and } \\
\text { benzene ring twisting }\end{array}$ \\
\hline \multirow[t]{2}{*}{$577(\mathrm{vw})$} & $595(w)$ & $\begin{array}{l}\text { in-plane } \rho(\mathrm{C}-\mathrm{O}-\mathrm{H}) \text { and benzene ring rocking; out-of-plane aromatic } \\
\text { chain } \omega\left(\mathrm{CH}_{2}\right) \text { and } \omega\left(\mathrm{CH}_{3}\right) \text { wagging }\end{array}$ \\
\hline & 620(w) & $\begin{array}{l}\text { out-of-plane } \tau(\mathrm{CH}) \text { twisting; } \omega(\mathrm{C}=\mathrm{C}-\mathrm{C}) \text { wagging; out-of-plane } \\
\text { aromatic chain } \omega\left(\mathrm{CH}_{2}\right) \text { and } \omega\left(\mathrm{CH}_{3}\right) \text { wagging }\end{array}$ \\
\hline 639(vw) & 640(m) & $\begin{array}{l}\text { out-of-plane } \tau(\mathrm{CH}) \text { twisting; } \omega(\mathrm{C}=\mathrm{C}-\mathrm{C}) \text { wagging; out-of-plane } \\
\text { aromatic chain } \omega\left(\mathrm{CH}_{2}\right) \text { and } \omega\left(\mathrm{CH}_{3}\right) \text { wagging }\end{array}$ \\
\hline $745(\mathrm{vw})$ & $756(s)$ & $\begin{array}{l}\text { in-plane } \delta \mathrm{s}(\mathrm{C}=\mathrm{C}-\mathrm{C}) \text { scissoring; } v\left(\mathrm{CH}_{2}\right) \text { stretching; } \\
\text { in-plane } v_{\mathrm{s}}(\mathrm{OH}) \text { symmetrical stretching }\end{array}$ \\
\hline 789(w) & $795(\mathrm{~s})$ & $\begin{array}{l}\text { in-plane } v_{\mathrm{s}}(\mathrm{C}-\mathrm{O}) \text { symmetrical stretching; in-plane } \delta \mathrm{s}(\mathrm{C}=\mathrm{C}-\mathrm{C}) \\
\text { scissoring; out-of-plane } \omega(\mathrm{C}-\mathrm{H}) \text { and } \omega\left(\mathrm{CH}_{3}\right) \text { wagging }\end{array}$ \\
\hline $851(\mathrm{vw})$ & $860(\mathrm{~m})$ & $\begin{array}{l}\text { out-of-plane } \omega(\mathrm{C}-\mathrm{H}) \text { wagging; } \rho\left(\mathrm{CH}_{2}\right) \text { rocking; aromatic chain } \\
v_{\mathrm{s}}\left(\mathrm{CH}_{2}\right) \text { and } v_{\mathrm{s}}\left(\mathrm{CH}_{3}\right) \text { stretching }\end{array}$ \\
\hline 956(w) & $956(\mathrm{~s})$ & $\begin{array}{l}\text { in-plane } v_{s}(\mathrm{C}=\mathrm{C}-\mathrm{C}) \text { and } v(\mathrm{C}-\mathrm{OH}) \text { stretching; aromatic } v\left(\mathrm{CH}_{2}\right) \\
\text { stretching; } \rho(\mathrm{C}-\mathrm{H}) \text { rocking; out-of-plane } \tau(\mathrm{C}-\mathrm{H}) \text { twisting; } \\
\text { out-of-plane } \omega\left(\mathrm{CH}_{3}\right) \text { wagging }\end{array}$ \\
\hline $1079(\mathrm{~m})$ & $1098(\mathrm{~s})$ & $\begin{array}{l}\text { in-plane } v(\mathrm{C}=\mathrm{C}) \text { stretching; } \rho(\mathrm{O}-\mathrm{H}) \text { rocking; } \rho\left(\mathrm{CH}_{3}\right) \text { rocking; } \\
\tau(\mathrm{C}-\mathrm{H}) \text { twisting }\end{array}$ \\
\hline $1098(\mathrm{~s})$ & $1112(\mathrm{~s})$ & $\begin{array}{l}\text { in-plane } \delta \mathrm{s}(\mathrm{C}=\mathrm{C}) \text { scissoring; } \rho(\mathrm{C}-\mathrm{O}-\mathrm{H}) \text { rocking; } \rho\left(\mathrm{CH}_{2}\right) \text { rocking; } \\
\rho\left(\mathrm{CH}_{3}\right) \text { rocking; in-plane } v_{\mathrm{s}}\left(\mathrm{CH}_{2}\right) \text { symmetrical stretching }\end{array}$ \\
\hline $1168(\mathrm{vs})$ & $1190(\mathrm{vs})$ & $\begin{array}{l}\text { in-plane strong } \rho(\mathrm{O}-\mathrm{H}) \text { rocking; in-plane } v_{\text {as }}(\mathrm{C}-\mathrm{H}) \text { and benzene ring } \\
\text { asymmetrical stretching; } \rho\left(\mathrm{CH}_{3}\right) \text { rocking }\end{array}$ \\
\hline $1256(\mathrm{~s})$ & 1251(s) & $\begin{array}{l}\text { out-of-plane } \tau(\mathrm{C}-\mathrm{H}) \text { twisting; out-of-plane } \rho\left(\mathrm{CH}_{3}\right) \text { rocking; } \\
\nu(\mathrm{C}-\mathrm{OH}) \text { stretching }\end{array}$ \\
\hline $1291(\mathrm{~s})$ & $1293(\mathrm{~s})$ & strong benzene ring breathing; $\rho(\mathrm{C}-\mathrm{H})$ rocking; $\rho\left(\mathrm{CH}_{2}\right)$ rocking; \\
\hline $1342(\mathrm{~m})$ & $1382(\mathrm{~s})$ & $\rho(\mathrm{O}-\mathrm{H})$ rocking; $\rho(\mathrm{C}-\mathrm{H})$ rocking; $\rho\left(\mathrm{CH}_{3}\right)$ rocking \\
\hline 1441(m) & $1445(\mathrm{~s})$ & $\begin{array}{l}\text { in-plane } v_{\text {as }}(\mathrm{C}-\mathrm{C}-\mathrm{O}) \text { strong stretching; } \rho(\mathrm{O}-\mathrm{H}) \text { rocking; } \\
\rho(\mathrm{C}-\mathrm{H}) \text { rocking; out-of-plane } \tau\left(\mathrm{CH}_{2}\right) \text { twisting }\end{array}$ \\
\hline $1525(\mathrm{~s})$ & $1525(\mathrm{~s})$ & $\begin{array}{l}\rho(\mathrm{C}-\mathrm{H}) \text { rocking; } \delta \mathrm{s}(\mathrm{C}-\mathrm{O}-\mathrm{H}) \text { scissoring; in-plane benzene ring } \\
\text { symmetrical stretching }\end{array}$ \\
\hline $1614(\mathrm{~m})$ & $1615(\mathrm{~s})$ & $\begin{array}{l}\text { in-plane strong benzene ring asymmetrical stretching; } \rho(\mathrm{O}-\mathrm{H}) \text { rocking; } \\
\delta \mathrm{s}(\mathrm{C}-\mathrm{O}-\mathrm{H}) \text { scissoring; out-of-plane } \tau\left(\mathrm{CH}_{2}\right) \text { twisting }\end{array}$ \\
\hline $2868(\mathrm{~m})$ & 2873(m) & in-plane strong $v_{\mathrm{s}}\left(\mathrm{CH}_{3}\right)$ and $v_{\mathrm{s}}\left(\mathrm{CH}_{2}\right)$ stretching; $\rho(\mathrm{C}-\mathrm{H})$ rocking; \\
\hline 2953(m) & $2935(\mathrm{~m})$ & in-plane $v_{\text {as }}\left(\mathrm{CH}_{3}\right)$ and vas $\left(\mathrm{CH}_{2}\right)$ stretching \\
\hline $2987(\mathrm{~m})$ & $2972(\mathrm{~m})$ & in-plane $v(\mathrm{C}-\mathrm{H})$ stretching; $\rho(\mathrm{C}-\mathrm{H})$ rocking \\
\hline $3530(\mathrm{~s})$ & $3472(\mathrm{~s})$ & in-plane $v(\mathrm{O}-\mathrm{H})$ strong stretching \\
\hline \multicolumn{2}{|c|}{$v_{\mathrm{as}}$ : asymmetric stretching; } & symmetric stretching; \\
\hline$\rho:$ in-plane $\mathrm{r}$ & ng; & $\tau:$ out-of-plane twisting \\
\hline
\end{tabular}

Catechols are known to oxidize [49,55-60]. It has also been reported that NDGA is unstable in aqueous media [56], with an autoxidation process more often occurring at higher $\mathrm{pH}$ [49]. Although a potential four-electron oxidation process would be most anticipated (most catechol derivatives follow the one-step two-electron redox reaction), experiments demonstrated a different behavior for NDGA electro-oxidation $[49,58,61]$. An initial formation of intermediate semi-quinonic radicals, mainly of cations through the compound fast deprotonation, which will subsequently transform to either para-quinone methide (one-step electron transfer) or ortho-quinone (one-step two-electron transfer) forms, has been suggested [58,61]. A simplified scheme of NDGA oxidation process is presented in Figure 3 with all forms appropriately labeled. Even though less likely, further oxidation of ortho-quinonic form through a second one-step two-electron transfer that will result in a fully oxidized NDGA is also incorporated in this scheme. 

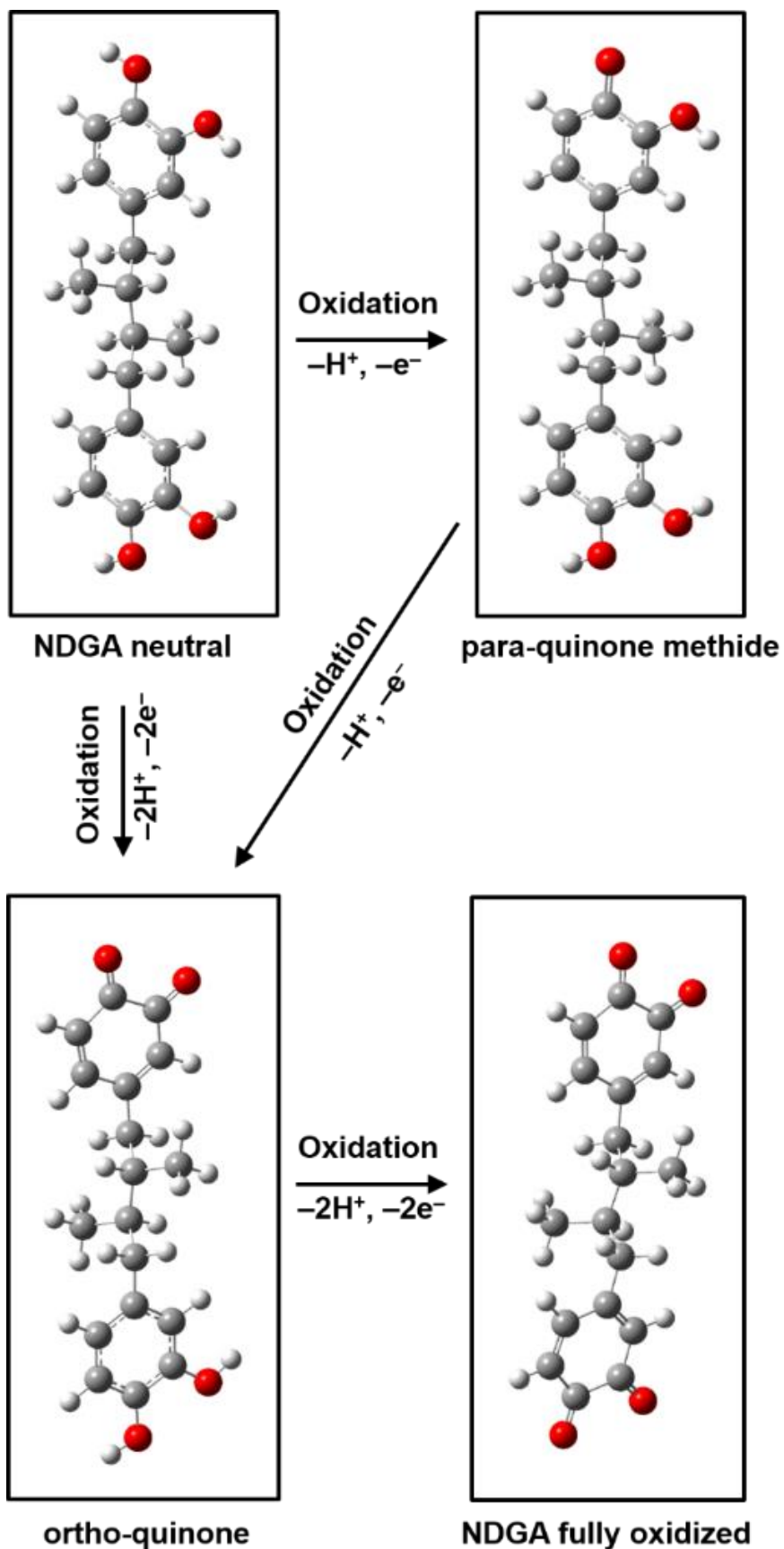

NDGA fully oxidized

Figure 3. Schematic oxidation process of NDGA consisting of para-quinone methide, ortho-quinone, and fully oxidized form, as labeled.

The Raman and FTIR computed outcomes, and the structural representations of NDGA for para-quinone methide, ortho-quinone, and fully oxidized configurations are presented in Figure 4A-D, Figure 5A-D, and Figure 6A-D, respectively. For easier visualization and identification of spectroscopic differences between these NDGA forms, the displacement vectors associated with the most intense vibrational modes observed for both Raman and IR, were again represented by blue arrows in Figures $4 \mathrm{~A}$ and $4 \mathrm{~B}$, Figures $5 \mathrm{~A}$ and $5 \mathrm{~B}$, and Figures $6 \mathrm{~A}$ and 6B. Also, for consistency with previous results, the same 0.98 scaling factor was applied to the calculated frequencies. Finally, only the $150-2000 \mathrm{~cm}^{-1}$ region was considered to potentially enable optical discrimination between these NDGA conformations, as water absorption spectroscopic features mainly dominate the higher frequency region. 

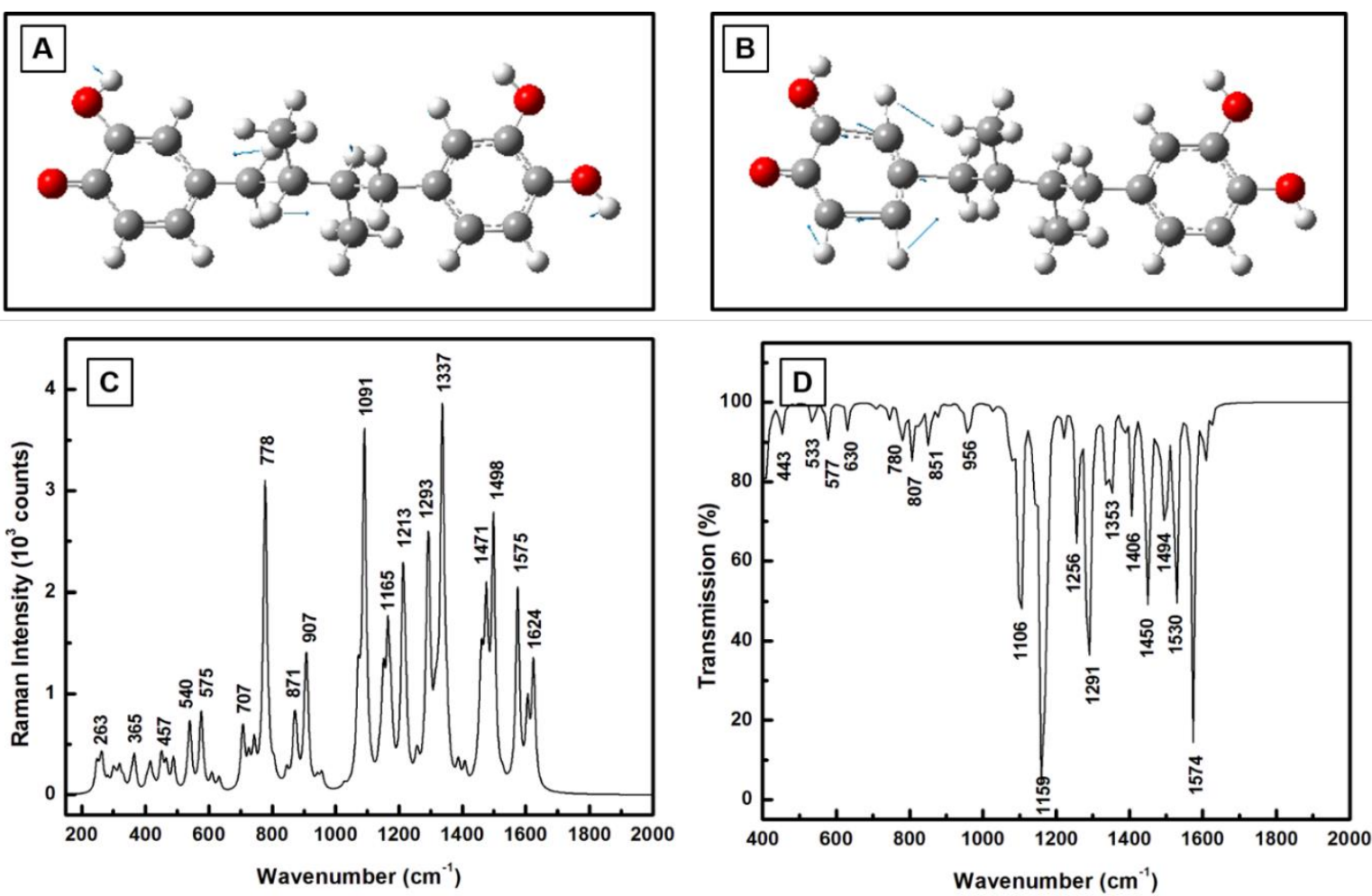

Figure 4. (A) and (B) Para-quinone methide structural representation of NDGA with displacement vectors incorporated by blue arrows for the most intense Raman vibration at $1337 \mathrm{~cm}^{-1}$ and IR vibration at $1159 \mathrm{~cm}^{-1}$, respectively. (C) and (D) Theoretically estimated Raman and IR vibrational spectra of para-quinone methide.

In addition to the Raman signature at $778 \mathrm{~cm}^{-1}$, which for neutral NDGA form was theoretically estimated at $785 \mathrm{~cm}^{-1}$ (see Figure 1B), a multitude of other intense Raman lines can be observed in the spectrum of para-quinone methide form at 907, 1091, 1165, 1213, 1293, $1337,1471,1498,1575$, and $1624 \mathrm{~cm}^{-1}$ (see Figure 4C). A similar spectroscopic activity is also seen in the IR spectrum of this form that is presented in Figure 4D, with a visible increase in the intensities of absorption lines at 1106, 1159, 1291, 1450, 1530, and $1574 \mathrm{~cm}^{-1}$ when compared to those of the neutral form (see Figure 2B). The strong presence in the spectra of para-quinone methide of both Raman and IR signatures characteristic to the neutral NDGA form could make a distinction between these two chemical structures challenging, especially from an experimental perspective. Although theoretically, there are evident shifts in the frequency locations of these vibrations (of $7 \mathrm{~cm}^{-1}$ in the case of Raman and of $9 \mathrm{~cm}^{-1}$ in the IR case), experimentally, these variations might not suffice for an accurate assignment of the NDGA conformation. Further complications in the validity of this assignment could also arise from other factors, such as the high chemical stability of the neutral form on the one hand, which could make this form more prone to exist, and the high NDGA affinity to bind to bioanalytes on the other hand, which could lead to a para-quinone methide morphological change. This challenging distinction can be overcome by considering other vibrations in the Raman and IR spectra of para-quinone methide shown in Figures 4C and 4D, respectively, besides the ones already attributed to the neutral form. Thus, to call attention to these vibrational differences, in Figures $4 \mathrm{~A}$ and $4 \mathrm{~B}$, we represent by blue arrows the displacement vectors for the Raman vibration at $1337 \mathrm{~cm}^{-1}$ and the IR vibration at $1574 \mathrm{~cm}^{-1}$. These displacement vectors indicate that the Raman vibrational mode at $1337 \mathrm{~cm}^{-1}$ is associated with the cathecols' deformation from in-plane $v(\mathrm{C}=\mathrm{C})$ stretching, $\rho(\mathrm{O}-\mathrm{H})$ and $\rho(\mathrm{C}-\mathrm{H})$ rocking, as well as with those from the aliphatic chain, such as $\rho\left(\mathrm{CH}_{2}\right)$ rocking and out-of-plane $\omega(\mathrm{C}-\mathrm{H})$ 
weak wagging. The $1574 \mathrm{~cm}^{-1}$ IR vibrational mode mainly contains strong $v(C=C)$ stretching, strong $\rho(\mathrm{C}-\mathrm{H})$ rocking, and weak $v(\mathrm{C}=\mathrm{O})$ stretching and $\rho(\mathrm{O}-\mathrm{H})$ rocking.
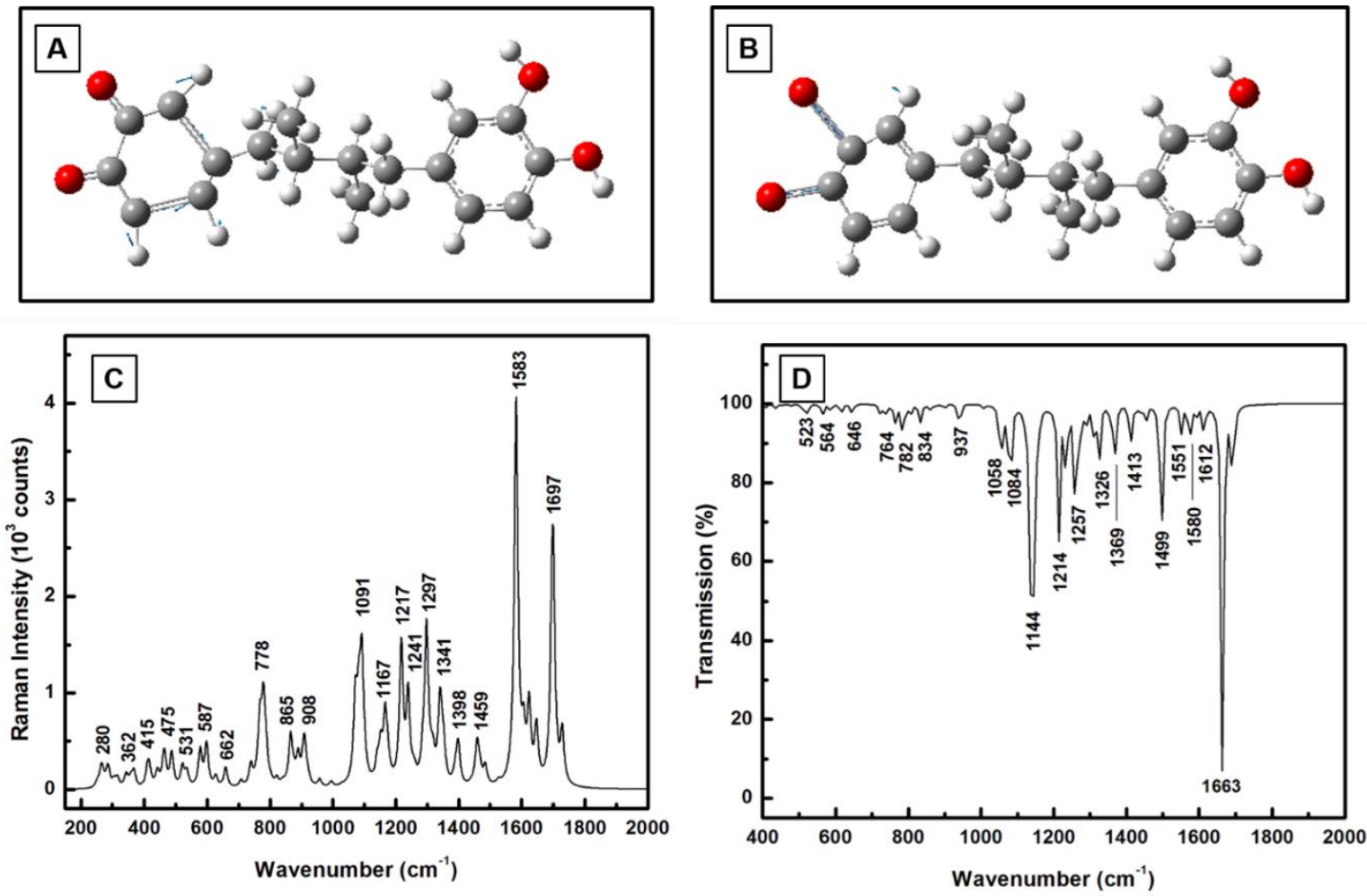

Figure 5. (A) and (B) Ortho-quinone structural representation of NDGA with displacement vectors incorporated by blue arrows for the most intense Raman vibration at $1583 \mathrm{~cm}^{-1}$ and IR vibration at $1663 \mathrm{~cm}^{-1}$, respectively.

(C) and (D) Theoretically estimated Raman and IR vibrational spectra of ortho-quinonic NDGA form.

A further change in the molecular structure of NDGA is spectroscopically revealed by Figures 5C and 5D, where the characteristic Raman and IR spectra of ortho-quinone form are presented. Although the $778 \mathrm{~cm}^{-1}$ Raman vibration is still present in Figure 5C, its intensity is noticeable lower than that seen in Figure $4 \mathrm{C}$ for the para-quinone methide. Much lower intensities are also observed in Figure 5C for all the Raman peaks in the $1000-1500 \mathrm{~cm}^{-1}$ frequency region, which become comparable in intensities with those of neutral form (see Figure 1B). Another obvious difference is the dramatic intensity increase of the 1583 and 1697 $\mathrm{cm}^{-1}$ Raman peaks, which can be considered as optical signatures for the ortho-quinone form. A comparison between the IR spectra of the ortho-quinone, which is shown in Figure 5D, with that of para-quinone methide, demonstrates a decrease in the intensity of $1144 \mathrm{~cm}^{-1}$ feature and a significant increase for the $1663 \mathrm{~cm}^{-1}$ absorption line. Since the vibrational lines around 1700 $\mathrm{cm}^{-1}$ frequency again correspond to the benzene ring's strong in-plane $v(C=O)$ and $v(C=C)$ stretching, $\rho(\mathrm{O}-\mathrm{H})$ rocking, and out-of-plane $\omega\left(\mathrm{CH}_{2}\right)$ wagging, they are added evidence to the NDGA's morphological transformation due to the oxidation process. The displacement vectors of the $1583 \mathrm{~cm}^{-1}$ Raman peak and $1663 \mathrm{~cm}^{-1}$ absorption line are represented by blue arrows in Figures $5 \mathrm{~A}$ and $5 \mathrm{~B}$, respectively.

Although a quick comparison between the Raman and IR spectra of ortho-quinone with those of fully oxidized NDGA form, which are presented in Figures 6C and 6D, respectively, does not show evident spectroscopic variances, a closer examination can establish that some differences still exist. For example, there is a much lower intensity of the frequently observed Raman vibrational line at $780 \pm 5 \mathrm{~cm}^{-1}$, which, in the case of fully oxidized NDGA, broadens, shifts to a lower frequency around $764 \mathrm{~cm}^{-1}$, and almost disappears. This behavior is a direct 
confirmation that the neutral form of NDGA completely oxidized. Also, a new spectroscopic change is the appearance of the absorption line at $1235 \mathrm{~cm}^{-1}$ in the IR spectrum (see Figure $6 \mathrm{D})$. Since this vibration is associated with asymmetric $v(\mathrm{C}-\mathrm{C})$ stretching and $\rho(\mathrm{O}-\mathrm{H})$ rocking of the catechols, and with the out-of-plane $\omega\left(\mathrm{CH}_{2}\right)$ wagging of the aliphatic chain, similar to the ortho-quinone's feature at $1144 \mathrm{~cm}^{-1}$ and that of the para-quinone methide at $1159 \mathrm{~cm}^{-1}$, it could be implied that in the case of a fully oxidized configuration, this line shifts to a much higher frequency, by $91 \mathrm{~cm}^{-1}$ and $76 \mathrm{~cm}^{-1}$, respectively.
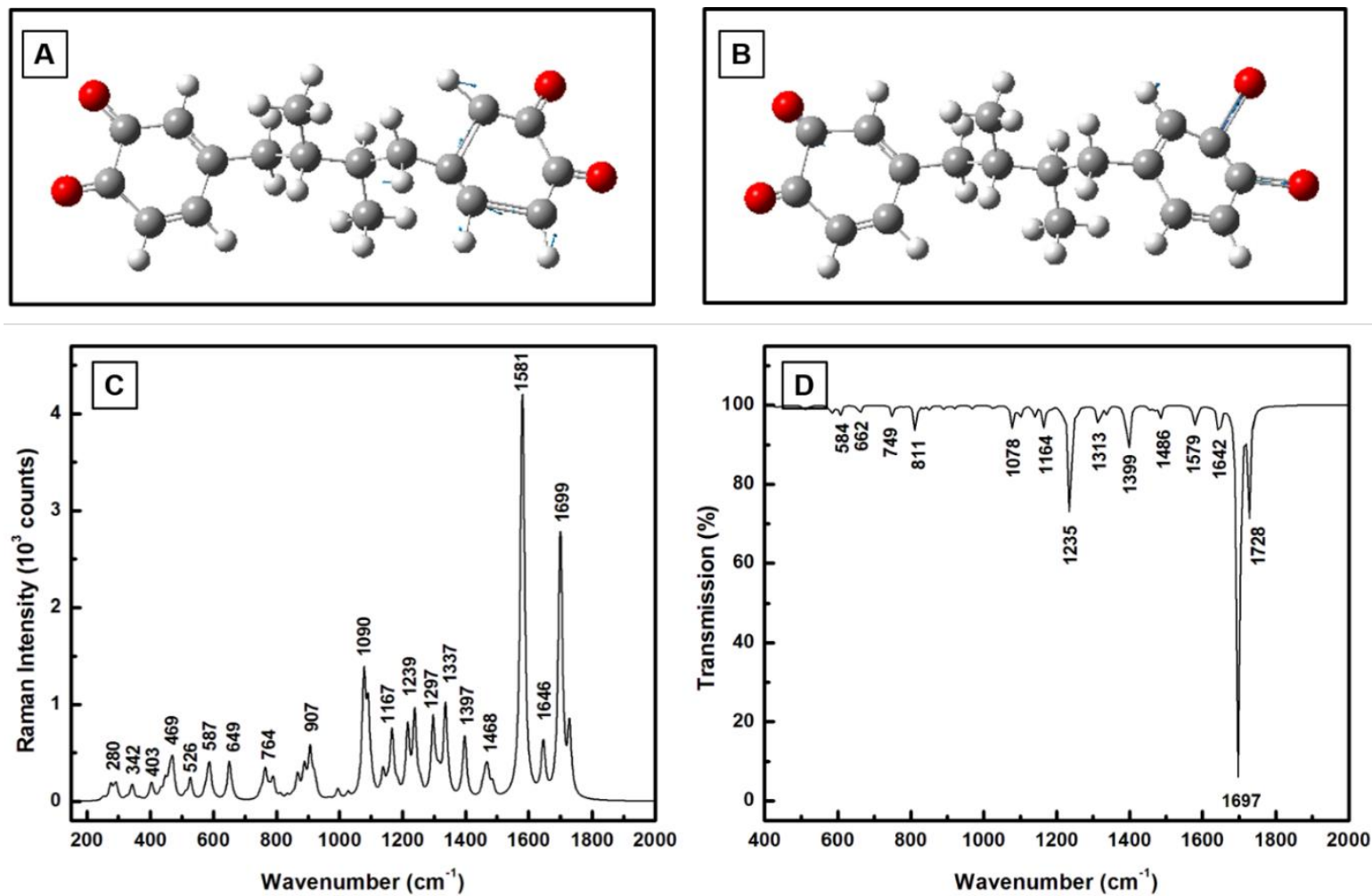

Figure 6. (A) and (B) Fully oxidized structural representation of NDGA with displacement vector incorporated by blue arrows for the most intense Raman vibration at $1581 \mathrm{~cm}^{-1}$ and IR vibration at $1697 \mathrm{~cm}^{-1}$, respectively.

(C) and (D) Theoretically estimated Raman and IR vibrational spectra of fully oxidized NDGA form.

The vibrational resemblance between the NDGA fully oxidized and ortho-quinone forms is emphasized in Figure 6A and 6B by representing with blue arrows the displacement vectors for the Raman signature at $1581 \mathrm{~cm}^{-1}$ and the IR at $1697 \mathrm{~cm}^{-1}$, respectively; they are still the dominant vibrational lines observed for both NDGA oxidized configurations. It has been suggested that at physiological levels of $\mathrm{pH} 7.4$ the ortho-quinone form dominates $[53,56]$. Not only was its formation associated with NDGA's biological activity, but also that its accumulation contributed to the compound in vivo toxicity $[53,56]$. Based on the current results, it can be inferred that a fully oxidized NDGA conformation would be more likely to generate the compound bio-toxicity through accumulation, as it would not undergo a further oxidative transformation. This supposition could be confirmed experimentally from the absence of the Raman band at about $780 \pm 5 \mathrm{~cm}^{-1}$.

\section{Conclusions}

Being an effective ROS scavenger, NDGA has been shown to have encouraging relevance in medication of various diseases, like neurological, cardiovascular, renal, pulmonary, cancer, and, more importantly, considering the current COVID-19 pandemic, towards a large variety of viruses. Its medicinal and antiviral properties have been supported 
by in vitro and in vivo experimental studies [18-49]. While this compound could be a potential candidate for new drug development, cautiousness should be considered, as it is in vivo accumulation that can also have negative health consequences. In an effort to optically provide additional insights into which NDGA morphological conformation offers health benefits and which one harms, we theoretically and experimentally analyze this compound by DFT calculations and by Raman and FTIR spectroscopic methods, respectively. We have succeeded in elucidating the vibrational signatures of different NDGA structural variations associated with its chemical changes upon oxidation. Definite trends in the spectroscopic signatures of these NDGA confirmations were observed. For example, the main vibrations detected for the neutral form at $785 \mathrm{~cm}^{-1}$ in the Raman spectrum (see Figure 1B) and at $1168 \mathrm{~cm}^{-1}$ in the IR spectrum (see Figure 2B), downshift in the case of para-quinone methide form to $778 \mathrm{~cm}^{-1}$ (see Figure 4C) and to $1159 \mathrm{~cm}^{-1}$ (see Figure 4D), respectively, dramatically decrease in intensities for ortho-quinone form (see Figures 5C and 5D), and almost disappear in the case of a fully oxidized form (see Figures 6C and 6D). On the other hand, other features become dominant as the oxidation process advances, such as the Raman vibrations at $1582 \pm 1 \mathrm{~cm}^{-1}$ and $1698 \pm 1$ $\mathrm{cm}^{-1}$ and the IR vibration at $1680 \pm 17 \mathrm{~cm}^{-1}$. While these remarks validate that a distinction between different NDGA forms can be achieved theoretically, experimentally, accurate assignments will remain challenging, but possible. Even though other factors such as the high stability of the neutral form and the high NDGA affinity to bind to analytes need to be considered, experimentally, the absence of the Raman band at about $780 \pm 5 \mathrm{~cm}^{-1}$ and the appearance of dominant vibrations around $1700 \mathrm{~cm}^{-1}$ frequency region, still will confirm the existence of a fully oxidized NDGA form. Based on the current results, this oxidized form is more likely to accumulate and to create the compound in vivo toxicity, in addition to the orthoquinone's contribution. More work needs to be done, especially involving a more complex biological environment, which is beyond the scope of this study. If the development of new drugs and their effective implementation is envisioned for the future, the current spectroscopic analysis provides some needed scientific background for comprehending changes in the vibrational signatures of this important biomedicinal, plant-derived compound.

\section{Funding}

This research was funded by the NIH U01 NS090455 award, The Grainger Foundation, and a research agreement between the Mayo Clinic and the University of Texas at El Paso.

\section{Acknowledgments}

The authors are grateful to the Texas Advanced Computing Center (TACC) for the CPU time allocation.

\section{Conflicts of Interest}

The authors declare no conflict of interest.

\section{References}

1. Arteaga, S.; Andrade-Catto, A.; Cardenas, R. Larrea tridentata (Creosote bush), an abundant plant of Mexican and US-American deserts and its metabolite nordihydroguaiaretic acid. J. Ethnopharmac. 2005, 98, 231-239, https://doi.org/10.1016/j.jep.2005.02.002.

2. Spencer, J.; Jacobson, J. Complementary, Alternative Medicine: An Evidence Based Approach. Mosby Inc., St. Louis MO, USA, 2003; pp. 69-482. 
3. Newall, C.A.; Anderson, L.A.; Phillipson, J.D. Herbal medicines. A guide for health-care professionals. Pharmaceutical Press, London, UK, 1996; pp. 28-390.

4. Grumezescu, A.M.; Holban, A.M. Value-Added Ingredients and Enrichments of Beverages. Woodhead Publishing, Elsevier Inc., Cambrige, MA, USA. Volume 14, 2019; pp. 487-514.

5. Ram, G.; Sharma,V.R.; Sheikh, I.; Sankhyan, A.; Aggarwal, D.; Sharma, A.K. Anti-cancer potential of natural products: recent trends, scope and relevance. Lett. Appl. NanoBioSci., 2020, 9(1), 2020, 902-907, https://doi.org/10.33263/LIANBS91.902907.

6. Rani, S.; Gahlot, K.; Kumar, A. Experimental evidences of antidiabetic activity of aqueous extract of Cressa cretica L. on streptozotocin induced diabetes in rats. Lett. Appl. NanoBioSci., 2020, 9(1), 774-778, https://doi.org/10.33263/LIANBS91.774778.

7. Prabhakar, P.K.; Nath, D.; Singh, S.; Mittal, A.; Dileep Singh Baghel, D.S. Formulation and evaluation of polyherbal anti-acne combination by using in-vitro model. Biointerface Res. Appl. Chem., 2020, 10(1), 4747-4751, https://doi.org/10.33263/BRIAC101.747751.

8. Waller, C.; Gisvold, O. A phytochemical investigation of Larrea diviricata Cav. J. Am. Pharm. Assoc. 1945, 34, 78-81, https://doi.org/10.1002/jps.3030340305.

9. Page, J.O. Determination of Nordihydroguaiaretic Acid in Creosote Bush. Anal. Chem. 1955, 27, 12661268, https://doi.org/10.1021/ac60104a017.

10. Perry, C.W.; Kalnins, M.V.; Deitcher, K.H. Synthesis of Lignans. I. Nordihydroguaiaretic Acid. J. Org. Chem. 1972, 37, 4371-4376, https://doi.org/10.1021/jo00799a605.

11. Manda, G.; Rojo, A.I., Martínez-Klimova, E.; Pedraza-Chaverri, J.; Cuadrado. A. Nordihydroguaiaretic Acid: From Herbal Medicine to Clinical Development for Cancer and Chronic Diseases. Front. Pharmacol. 2020, 11, 1-21, https://doi.org/10.3389/fphar.2020.00151.

12. Goodman, T.; Grice, H.C.; Becking, G.C.; Salem, F.A. A cystic nephropathy induced by nordihydroguaiaretic acid in the rat. Light and electron microscopic investigations. Lab. Invest. 1970, 23, 93-107.

13. Abou-Gazar, H.; Bedir, E.; Takamatsu, S.; Ferreira, D.; Khan, I.A. Antioxidant ligans from Larrea tridentate. Phytochem. 2004, 65, 2499-2505, https://doi.org/10.1016/j.phytochem.2004.07.009.

14. Rodriguez-Fragoso, L.; Reyes-Esparza, J.; Burchiel, S.W.; Herrera-Ruiz, D.; Torres, E. Risks and benefits of commonly used herbal medicines in Mexico. Toxicol. Appl. Pharmacol. 2008, 227, 125-135, https://doi.org/10.1016/j.taap.2007.10.005.

15. Kono, C.; Lu, Z.; Xue, H.; Erdelmeier, C.; Meksuriyen, D.; Che, C.; Cordell, G.; Soejarto, D.; Waller, D.; Fong, H.H. Furanoid lignans from Larrea tridentata. J. Nat. Prod. 1990, 53, 396-406, https://doi.org/10.1021/np50068a019.

16. Lambert, J.D.; Shengmin, S.; Dougherty, A.; Caldwell, C.G.; Meyers, R.O.; Dorr, R.T.; Timmermann, B.N. Cytotoxic lignans from Larrea tridentate. Phytochem., 2005, 66, 811-815, https://doi.org/10.1016/j.phytochem.2005.02.007.

17. Luo, J.; Chuang, T.; Cheung, J.; Quan, J.; Tsai, J.; Sullivan, C.; Hector, R.F.; Reed, M.J.; Meszaros, K.; King, S.R.; Carlson, T.J.; Reaven, G.M. Masoprocol (nordihydroguaiaretic acid): a new antihyperglycemic agent isolated from the creosote bush (Larrea tridentata). Eur. J. Pharmacol. 1998, 346, 77-79, https://doi.org/10.1016/s0014-2999(98)00139-3.

18. Lambert, J.D.; Dorr, R.T.; Timmermann, B.N. Nordihydroguaiaretic Acid: A Review of Its Numerous and Varied Biological Activities. Pharmac. Biol. 2004, 42, 149-158, https://doi.org/10.1080/13880200490512016.

19. Mundhe, N.; Kumar, P.; Arora, I.; Ahmed, S.; Lahkar, M. Differential effect of NDGA on cisplatin-induced nephrotoxicity in Spargue-Dawley rats. Immunopharmacol. Immunotoxicol. 2019, 41, 68-75, https://doi.org/10.1080/08923973.2018.1547741.

20. Hwu, J.R.; Tseng, W.N.; Gnabre, J.; Giza, P.; Huang, R.C. Antiviral activities of methylated nordihydroguaiaretic acids. 1. Synthesis, structure identification, and inhibition of tat-regulated HIV transactivation. J. Med. Chem. 1998, 41, 2994-3000, https://doi.org/10.1021/jm970819w.

21. Daniels, M.J.; Brucker Nourse Jr., J.; Kim, H.; Sainati, V.; Schiavina, M.; Murrali, M.G.; Pan, B.; Ferrie, J.J.; Haney, C.M.; Moons, R.; Gould, N.S.; Natalello, A.; Grandori, R.; Sobott, F.; Petersson, E.J.; Rhoades, E.; Pierattelli, R.; Felli, I.; Uversky, V.N.; Caldwell, K.A.; Caldwell, G.A.; Krol, E.S.; Ischiropoulos, H. Cyclized NDGA modifies dynamic $\alpha$-synuclein monomers preventing aggregation and toxicity. Scientific Rep. 2019, 9, 2937-2954, https://doi.org/10.1038/s41598-019-39480-z.

22. Ono, K.; Hasegawa, K.; Yoshiike, Y.; Takashima, A.; Yamada, M.; Naiki, H. Nordihydroguaiaretic acid potently breaks down pre-formed Alzheimer's $\beta$-amyloid fibrils in vitro. J. Neurochem. 2002, 81, 434-440, https://doi.org/10.1046/j.1471-4159.2002.00904.x.

23. Lü, J.M.; Nurko, J.; Weakley, S.M.; Jiang, J.; Kougias, P.; Lin, P.H.; Yao, Q.; Chen, C. Molecular mechanisms and clinical applications of nordihydroguaiaretic acid (NDGA) and its derivatives: an update. Med. Sci. Monit. 2010, 16, RA93-RA100.

24. Manciu, F.S.; Ciubuc, J.D.; Ochoa, K.; Dacha, P.; Subedi, M.; Guerrero, J.; Eastman, M.; Hodges, D.R.; Bennet, K.E. Comparative spectroscopic analysis of nordihydroguaiaretic acid and related natural products 
to inhibition of calcium oxalate calculi. Biointerface Res. Appl. Chem., 2019, 9(3), 3942-3948, https://doi.org/10.33263/BRIAC93.942948.

25. Manciu, F.S.; Govani, J.R.; Durrer, W.G.; Reza, L.; Pinales, L.A. Inhibition of urinary calculi - a spectroscopic study. J. Raman Spectrosc. 2009, 40, 861-865, https://doi.org/10.1002/jrs.2183.

26. Kimura, K.; Huang, R.C.C. Tetra-O-Methyl Nordihydroguaiaretic Acid Broadly Suppresses Cancer Metabolism and Synergistically Induces Strong Anticancer Activity in Combination with Etoposide, Rapamycin and UCN-01. Plos One 2016, 11, 1-28, https://doi.org/10.1371/journal.pone.0148685.

27. Zhang, H.; Shen, W.S.; Cortez, Y. Kraemer, F.B.; Azhar, S. Nordihydroguaiaretic acid improves metabolic dysregulation and aberrant hepatic lipid metabolism in mice by both PPAR $\alpha$-dependent and -independent pathways. Am. J. Physiol. Gastrointest. Liver Physiol. 2013, 304, G72-G86, https://doi.org/10.1152/ajpgi.00328.2012.

28. Redmond, W.J.; Camo, M.; Mitchell, V.; Vaughan, C.W.; Connor, M. Nordihydroguaiaretic acid activates hTRPA1 and modulates behavioral responses to noxious cold in mice. Pharmacol. Res. Perspect. 2014, 2, e00079, 1-10, https://doi.org/10.1002/prp2.79.

29. Diaz-Gerevini, G.T.; Dain, A.; Pasqualini, M.E.; Lopez, C.B.; Eynard, A.R. Repossi, G. Diabetic encephalopathy: beneficial effects of supplementation with fatty acids omega3 and nordihydroguaiaretic acid in a spontaneous diabetes rat model. Lipids Health Dis. 2019, 18, https://doi.org/10.1186/s12944-018-09387.

30. Singh, M.; Bittner, S.; Li, Y.; Bittner, A.; Han, L.; Cortez, Y.; Inayathullah, M.; Arif, Z.; Parthasarathi, R.; Rajadas, J.; Shen, W.-J.; Nicolls, M.R.; Kraemer, F.B.; Azhar, S. Anti-hyperlipidaemic effects of synthetic analogues of nordihydroguaiaretic acid in dyslipidaemic rats. Br. J. Pharmacol. 2019, 176, 369385, https://doi.org/10.1111/bph.14528.

31. Huang, L.; Wang, J.; Chen, L.; Zhu, M.; Wu, S.; Chu, S.; Zheng, Y.; Fan, Z.; Zhang, J.; Li, W.; Chen, D.; Yang, X.; Wang, S.; Qiu, P.; Wu, J. Design, Synthesis, and Evaluation of NDGA Analogues as Potential Anti-Ischemic Stroke Agents. Eur. J. Med. Chem. 2018, 143, 1165-1173, https://doi.org/10.1016/j.ejmech.2017.09.028.

32. Chan, J.K.W.; Bittner, S.; Bittner, A.; Atwal, S.; Shen, W.J.; Inayathullah, M.; Rajada, J.; Nicolls, M.R.; Kraemer, F.B.; Azhar, S. Nordihydroguaiaretic acid, a lignan from larrea tridentata (Creosote Bush), protects against american lifestyle-induced obesity syndrome diet-induced metabolic dysfunction in mice. $J$. Pharmacol. Exp. Ther. 2018, 365, 281-290. https://doi.org/10.1124/jpet.117.243733.

33. Asiamah, I.; Krol, E.S. Quadrupole linear ion-trap mass spectrometry studies on glutathione conjugates of nordihydroguaiaretic acid (NDGA) analogues reveals phenol-type analogues are without reactive metabolite-mediated toxic liability. Cogent. Chem. https://doi.org/10.1080/23312009.2018.1562858.

34. Cenini, G.; Lloret, A.; Cascella, R. Oxidative Stress in neurodegenerative diseases: from a mitochondrial point of view. Oxid. Med. Cell Longev. 2019, 2019, https://doi.org/10.1155/2019/2105607.

35. Soto, A.R.; Bautista, C.P.; Syed, G.H.; Siddiqui, A.; Del Angel, R.M. Nordihydroguaiaretic acid (NDGA) Inhibits Replication and Viral Morphogenesis of Dengue Virus. Antivir. Res. 2014, 109, 132-140, https://doi.org/10.1016/j.antiviral.2014.07.002.

36. Suwanmanee, S.; Surasombatpattana, P.; Soonthornworasiri, N.; Hamel, R.; Maneekan, P.; Misse, D.; Luplertlop, N. Monitoring arbovirus in Thailand: Surveillance of dengue, chikungunya and zika virus, with a focus on coinfections. Acta Tropica, 2018, 188, 244-250, https://doi.org/10.1016/j.actatropica.2018.09.012.

37. Syed, G.H.; Siddiqui, A. Effects of Hypolipidemic Agent Nordihydroguaiaretic Acid on Lipid Droplets and Hepatitis C Virus. Hepatology 2011, 54, 1936-1946, https://doi.org/10.1002/hep.24619.

38. Merino-Ramos, T.; de Oya, N.J.; Saiz, J.C.; Martín-Acebes, M.A. Antiviral Activity of Nordihydroguaiaretic Acid and Its Derivative Tetra-O-Methyl Nordihydroguaiaretic Acid against West Nile Virus and Zika Virus. Antimicrob. Agents Chemother. 2017, 61, https://doi.org/10.1128/AAC.00376-17.

39. Wang, S.; Le, T.Q.; Kurihara, N.; Chida, J.; Cisse, Y.; Yano, M.; Kido, H. Influenza Virus-Cytokine-Protease Cycle in the Pathogenesis of Vascular Hyperpermeability in Severe Influenza. J. Infect. Dis. 2010, 202, 9911001, https://doi.org/10.1086/656044.

40. Bugert, J.J.; Hucke, F.; Zanetta, P.; Bassetto, M.; Brancale, A. Antivirals in medical biodefense. Virus Genes 2020, 56, 150-167, https://doi.org/10.1007/s11262-020-01737-5.

41. Oyegunwa, A.O.; Sikes, M.L.; Wilson, J.R.; Scholle, F.; Laster, S.M. Tetra-O-methyl nordihydroguaiaretic acid (Terameprocol) inhibits the NF-kappaB-dependent transcription of TNF-alpha and MCP-1/CCL2 genes by preventing RelA from binding its cognate sites on DNA. J. Inflamm. 2010, 7, https://doi.org/10.1186/1476-9255-7-59.

42. Chen, H.; Teng, L.; Li, J.N.; Park, R.; Mold, D.E.; Gnabre, J.; Hwu, J.R.; Tseng, W.N.; Huang, R.C.C. Antiviral Activities of Methylated Nordihydroguaiaretic Acids. 2. Targeting Herpes Simplex Virus Replication by the Mutation Insensitive Transcription Inhibitor Tetra-O-methyl-NDGA. J. Med. Chem. 1998, 41, 3001-3007, https://doi.org/10.1021/jm980182w.

43. Cui, Q.; Du, R.; Liu, M.; Rong, L. Lignans and Their Derivatives from Plants as Antivirals. Molecules, 2020, 25, 183-200, https://doi.org/10.3390/molecules25010183. 
44. Biswal, S.S.; Datta, K.; Shaw, S.D.; Feng, X.; Robertson, J.D.; Kehrer, J.P. Glutathione oxidation and mitochondrial depolarization as mechanisms of nordihydroguaiaretic acid-induced apoptosis in lipoxygenase-deficient FL5.12 cells. Toxicol. Sci. 2000, 53, 77-83, https://doi.org/10.1093/toxsci/53.1.77.

45. Obermeyer, W.; Musser, S.; Betz, J.; Casey, R.; Pohland, A.; Page, S. Chemical studies of phytoestrogens and related compounds in dietary supplements: flax and chaparral. Proceed. Soc. Exper. Biol. Med. 1995, 208, 6-12, https://doi.org/10.3181/00379727-208-43824.

46. Timmermann, B. Practical uses of Larrea. In: Creosote Bush. Biology and Chemistry of Larrea in New World Deserts. Eds: Mabry, T.; Hunziker, J.; Difeo, D. Dowden Hutchinson Ross Inc., Pennsylvania, PA, USA, 1977; pp. 252-257.

47. Schrecker, A.W. Moso-Dihydroguiaretic Acid and its Derivatives. J. Amer. Chem. Soc. 1957, 3823.

48. Nusrat, S.; Siddiqi, M.K.; Zaman, M.; Zaidi, N.; Ajmal, M.R.; Alam, P.; Qadeer, A.; Abdelhameed, A.S.; Khan, R.H. A Comprehensive Spectroscopic and Computational Investigation to Probe the Interaction of Antineoplastic Drug Nordihydroguaiaretic Acid with Serum Albumins. Plos One 2016, 11, e0158833, 1-20, https://doi.org/10.1371/journal.pone.0158833.

49. Galano, A.; Macias-Ruvalcaba, N.A.; Medina Campos, O.N.; Pedraza-Chaverri, J. Mechanism of the OH Radical Scavenging Activity of Nordihydroguaiaretic Acid: A Combined Theoretical and Experimental Study. J. Phys. Chem. B 2010, 114, 6625-6635, https://doi.org/10.1021/jp912001c.

50. Becke, A.D. Density-functional thermochemistry. III. The role of exact exchange. J. Chem. Phys. 1993, 98, 5648-5652, https://doi.org/10.1063/1.464913.

51. Lee, C.; Yang, W.; Parr, R.G. Development of the Colle-Salvetti correlation-energy formula into a functional of the electron density. Phys. Rev. B 1988, 37, 785-789, https://doi.org/10.1103/PhysRevB.37.785.

52. Polavarapu, P.L. Ab initio vibrational Raman and Raman optical activity spectra. J. Phys. Chem. 1990, 94 , 8106-8112, https://doi.org/10.1021/j100384a024.

53. Krishnakumar, V.; Keresztury, G.; Sundius, T.; Ramasamy, R. Simulation of IR and Raman spectra based on scaled DFT force fields: A case study of 2-(methylthio)benzonitrile, with emphasis on band assignment. J. Mol. Struct. 2004, 702, 9-21, https://doi.org/10.1016/j.molstruc.2004.06.004.

54. Pande, S.; Jana, S.; Sinha, A.K.; Sarkar, S.; Basu, M.; Pradhan, M.; Pal, A.; Chowdhury, J.; Pal, T. Dopamine molecules on Aucore-Agshell bimetallic nanocolloids: Fourier transform infrared, Raman, and surfaceenhanced Raman spectroscopy study aided by density functional theory. J. Phys. Chem. C 2009, 113, 69897002, https://doi.org/10.1021/jp810210a.

55. Pulay, P. Applications of Electronic Structure Theory. In: Modern Theoretical Chemistry. Volume 4, Ed: Schaefer, H.F. Plenum, New York, NY, 1997; pp. 296.

56. Ciubuc, J.D.; Qiu, C.; Bennet, K.E.; Alonzo, M.; Durrer, W.G.; Manciu, F.S. Raman Computational and Experimental Studies of Dopamine Detection. Biosensors 2017, 17, 43-55, https://doi.org/10.3390/bios7040043.

57. Manciu, F.S.; Manciu, M.; Ciubuc, J.D.; Sundin, E.M.; Ochoa, K.; Eastman, M.; Durrer, W.G.; Guerrero, J.; Lopez, B.; Subedi, M.; Bennet, K.E. Simultaneous Detection of Dopamine and Serotonin - a Comparative Experimental and Theoretical Study of Neurotransmitter Interactions. Biosensors 2019, 9, https://doi.org/10.3390/bios9010003.

58. Billinsky, J.L.; Marcoux, M.R.; Krol, E.S. Oxidation of the Lignan Nordihrydroguaiaretic Acid. Chem. Res. Toxicol. 2007, 20, 1352-1358, https://doi.org/10.1021/tx700205j.

59. Sundin, E.M.; Ciubuc, J.D.; Bennet, K.E.; Ochoa, K.; Manciu, F.S. Comparative Computational and Experimental Detection of Adenosine Using Ultrasensitive Surface-Enhanced Raman Spectroscopy. Sensors 2018, 18, 2696-2711, https://doi.org/10.3390/s18082696.

60. Manciu, F.S.; Oh, Y.; Barath, A.S.; Rusheen, A.E.; Kouzani, A.Z.; Hodges, D.R.; Guerrero, J.; Tomshine, J.R.; Lee, K.H.; Bennet, K.E. Analysis of Carbon-based Microelectrodes for Neurochemical Sensing. Materials 2019, 12, 3186-3199, https://doi.org/10.3390/ma12193186.

61. Wagner, P.; Lewis, R.A. Interaction between activated nordihydroguaiaretic acid and deoxyribonucleic acid. Biochem. Pharmacol. 1980, 29, 3299-3306, https://doi.org/10.1016/0006-2952(80)90307-X. 